\title{
TRANSLATING THE NATION, TRANSLATING THE SUBALTERN
}

\section{MEENA T PILLAI}

Abstract: Subaltern Studies as history from the lower rungs of society is marked by a freedom from the restrictions imposed by the nation state. Gramsci speaks of the subaltern's incapability to think of the nation. Once it becomes possible for the subaltern to imagine the state, he transcends the conditions of subalternity. It is interesting in this context to note that subaltern writings are read in translation either in English or in the dominant regional language. As the liberal humanist, bourgeois values of the modern nation state seep into subaltern languages, they either get translated and appropriated or are subverted and rejected. The latter is a conscious political act in the discursive field of language, which gives a distinct speaking voice to the subalterns whose attempt at linguistic freedom becomes an act of post-colonial insurgency. In the former case there is an inscription of the nation into subaltern consciousness and vice versa. Subaltern translations of the lingo of nationalism thus become an act of cultural displacement. Claiming the nation in language also means being claimed by the nation. This paper seeks to study how nationalism and the concept of the nation state get translated in subaltern writings in regional languages in the process of translating/mediating the very 
condition of subalternity. It purports to compare two texts in Malayalam, Narayan's Kocharethi and K.J. Baby's Mavelimanrom, both of which attempt a subaltern re-imagining of the Indian State from the margins. Mavelimanrom consists of dispersed moments and fragments of history of the Adiyor tribe of Wayanad. It attempts to create an imagined community in the subaltern language and memory. Kocharethi, on the other hand, encloses a space of transition from the colonial to the post-colonial within the imagined boundaries of the nation state. A comparison of these two texts would be an exercise in contrast with the "sheer heterogeneity of decolonised space" and an exploration of the subtle nuances of the problem raised in subaltern translations of the nation.

A literary text validates a language, the writing or reading of which entails a subject positioning. A consciousness of subject positions and voices can re-empower languages, deconstruct histories, and create new texts of more dense dialogical accomplishment. Part of the project of postcolonial theory would be to push literary texts into this shifting arena of discursiveness, thus enabling new stands of counternarratives and countercontexts to shape themselves and complicate binarist histories. This could be the reason why post-colonial theory assigns so much significance to the act of translation, which is seen, not as a peaceful dialogue among equals, but as a cultural and political practice, appropriating or resisting ideological discourses, constructing or subverting canons thus exposing the derivativeness and heterogeneity of both linguistic and cultural material. 
This paper analyses two subaltern narratives, one of which displays a consciousness of the social hierarchies of dominant narratives of power and the need to implement discursive strategies to resist translation and thus evolve what Deleuze and Guattari would call 'a line of escape', while the other, in contrast, fails to tap on linguistic and cultural differences of the target culture, thus being implicated and performing the vanishing act of the subaltern, indicating the translatability of the subaltern identity into the master language of the nation.

Mavelimanrom (1991) by K.J. Baby is a novel in Malayalam, consisting of dispersed moments and fragments of history of the Adiyor tribe of Wayanad. It documents a moment of their past, thus allowing the Adiyors to speak and talk back to the powers that marginalized them, by searching for a hidden past, fragmentary testimonials and lost moments. The novel seeks to restore the integrity of indigenous histories that appear naturally in nonlinear, oral, symbolic, vernacular forms.

It is an attempt to create an imaginary community in the subåltern language and memory. By reviving customs, rituals, myth and folklore Mavelimanrom attempts to configure an imaginary homeland for the Adiyors. In the tale narrated by the tribe elder Jevarapperumon to Ira, the woeful plight of their homeland unfolds itself.

'Manrom' denotes a tribe with reference to its spatial location. This narration of an alternative space is also a repudiation of the hegemonic structure of the 'nation' imposed on the subalterns. The imagined utopia of Mavelimanrom 
problematizes the other imagined nation of 'India', simultaneously resisting and questioning all discourses narrating the nation. The text, thus, at one level, grapples with the problem of 'colonial historiography' and 'cultural amnesia' that critics like G.N. Devy lament, which are inherent in the construction of nation states. Mavelimanrom seeks to redeem the subalterns of this amnesia and to remind the reading subject that there is no essential, historical, homogenized Indianness.

Mavelimanrom could be called an exercise in what Lyotard calls 'anamnesis' or a psychoanalytic procedure, which requires the patients to "elaborate their current problems by freely associating apparently inconsequential details with past situations - allowing them to uncover hidden meanings in their lives and their behaviours". Through this psychotherapy in and of memory the subaltern subject attempts a cultural, historical and psychological recuperation. Language becomes the painful medium of remembering, of confronting the ghosts of the past, to exorcise them in the present.

The novel is marked by a consciousness of the nationalist agenda to undermine and marginalize the subaltern resistance to British colonialism. The story unfolds during the time of territorial imperialism, when the East India Company had joined hands with feudalism to reinstate new modes of discrimination and power over subject populations. The novel begins with the leasing of a slave 'Kaippadan' to a new Master Subbayyapattar by his old feudal Lord Ambu Nair. One can read the re-empowering of old feudal systems within the imperial economy of the East India Company's exploitative agenda. Mavelimanrom attempts to afford the subaltern agency. 
by rejecting the grand narratives of both imperialism and nationalism. By providing alternating ways of imagining/imaging community, it destabilizes the nationalist project. It attempts a renewal of images of the past through a discourse of the native subject as inscribed in histories of insurgency against colonial rule and as inscripted in popular memory and oral traditions. Since the insurrection of the Adiyors and Kurichiars of Wayanad was not a calculated political move for forging the energies of nation building, it does not find mention in elite discourses of anti-colonial movements or official archives. The insurgency of Pazhassi Raja finds special mention in the text as a breach between popular dissidence and imperial power. Whereas official history propagated the fact that Pazhassi was betrayed by a Kurichiyan, it was recorded later on that he was sold out by the feudal lords to the East India Company, which led to his downfall and execution.In A. Sreedhara Menon's A Survey of Kerala History the revolt of Kerala Varma Pazhassi Raja is written under the chapter title "The Challenge to British Supremacy". Pazhassi Raja was a king of the Kottayam Royal family who organized serious revolts against the British in Malabar in the late $18^{\text {th }}$ century on account of their misdirected revenue policy. In the Pazhassi Revolt of 1793-1797 Pazhassi Raja scored a decisive victory over the British who suffered a critical loss of men and material and a truce was called for as a matter of political expediency. The second Revolt took place from 1800 to 1805 and this time the Raja was assisted by the Kurichiyar leader Talakkal Chandu. The war took the nature of guerilla warfare waged in the jungles of Wayanad. In 1804, Talakkal Chandu, the Kurichiyar hero was captured. On $30^{\text {th }}$ November 1805, the Raja was shot dead by the British. 
Mavelimanrom contests these nationalist histories which, by privileging the role of Pazhassi Raja, never acknowledged native dissent and signs of resistance. As Spivak points out, "if the story of the rise of nationalist resistance to imperialism is to be disclosed coherently, it is the role of the indigenous subaltern that must be strategically excluded". Thus it is that there is an attempt to erase from history the valiant struggles of the Kurichiars under Pazhassi Raja. Mavelimanrom attempts to dismantle this notion of nationalism as "the only discourse credited with emancipatory possibilities" in the imperialist theatre and to write back into history "the subaltern examples of resistance throughout imperialist and pre-imperialist centuries".

It illustrates the politicality of literature in a postcolonial context whereby the author reworks a historical moment to resist colonialism. and its effects, and contests through language its discourses and hierarchies. Kaippadan and Ira's flight is marked by a desire to escape the landscape of oppression ('thampuranpadam' or the lord's fields) crossing hegemonic boundaries and structures that create unequal relations of power.

Mavelimanrom records the history of subalterns subjected to humiliation, cruelty and death. Theirs is a different version of identity, which has been elided over in history and it is this slippage that the text addresses. By delving on the subaltern craving for identity, expressed in a different language of experience and subjectivity, the text insists upon a representation of their quest in terms of political and personal power. Thus the novel becomes an attempt to 
revive the mythology of a people without history, or whose history was being threatened with erasure even from memory.

Placed in the context of the Hegelian master-slave dialectics, the novel attempts to turn the gaze of the master on himself. The moment of reverting the Other's gaze is also a moment of recognition of the consciousness from knowing one's self as the translated self to knowledge of the self as untranslatable. The concept of 'manrom' defines a special construct where the will to liberty overpowers even the will to life, a space where the slave de-codes the master's secret, the secret of the 'Other's' look, which moulds the 'self' to its state of servitude. The spatial and temporal construct of the 'manrom', thus, cannot but repudiate colonialism's narratives of power and its project of civilizing the native, the theoretical underpinning of which is a resistance to the overarching narratives of nationalism. Nations and nationalisms are also constituted within a colonial grammar. In its efforts to imagine a precolonial moment of history, Mavelimanrom thus has to preclude the seepages of the imaginary essence of the nation, in short, to resist translating the nation.

The native of Mavelimanrom is the victim both of an imperial ideology and feudal authority. And yet the myth of the 'manrom' is posited as a haven of refuge for the dispersed, dispossessed and dislocated subjectivities of natives who refuse to be consigned to their subject positions within the framework of the ruling ideologies of imperialism and feudalism. Such polysemic, anti-colonial subjectivities and their energies, which defy the definitions of the colonizer, are muted and translated into a monolithic national identity, articulated in the rhetoric of 'Nationalism' in Kocharethi, a 
Malayalam novel on the 'Malayaraya' tribe by Narayan (Narayan :1998).

While Mavelimanrom is set in the period of capitalist territorial colonialism and imperialism, Kocharethi takes place at the fag end of this phase, in the early half of the $20^{\text {th }}$ century. It encloses a space of transition from the colonial to the postcolonial within the imagined boundaries of the nation state. Thus, situated in a later milieu of Indian history, Kocharethi in a way addresses the questions of acculturation and education of the subaltern, in short, of the subaltern's translation as 'appropriation'. Education as a necessary ploy for moulding homogenous identities came packaged with the label promising equality and liberty. But the subaltern aspires for education in order to be liberated from the land and its woes. Kocharethi is filled with the new subaltern dream of a government job. Narayan makes a feeble attempt to parody this process of 'modernizing' the tribal. But the novel fails in demarcating a political position opposing colonial modernity. The discourse of nationalism with its dichotomies of material/spiritual, inner/outer, resurfaces again and again in the novel with obvious privileging of the spiritual and inner.

The novel Mavelimanrom is imbued with the knowledge and critique of imperialism as the ugly face of a particular kind of nationalism. Kocharethi reveals the slow acculturation of the native into the economy, culture and politics of the nation state. The native in Kocharethi falls prey to the project of colonial modernity, which the new Indian state sets out to continue in order to prove its capability to selfrule. As Partha Chatterjee points out, Indian nationalism thus "produced a discourse of which, even as it challenged the 
colonial claim to political domination, also accepted the very intellectual premise of 'modernity' on which colonial domination was based".

Kocharethi depicts the plight of the native subaltern caught in the regulative politics of the infallible nation state, and betrayed by the promise of the participatory citizenship, struggling to find voice amidst the homogenized Babel of nationalist discourses. Mavelimanrom, in contrast, is a critique of the totalizing forms of nationalist historicism. It aims to regain the native's control over his/her own geography, language, literature and history. Kocharethi is a case in point of the 'hybridity' of the 'colonialist text' when the subject constitution of the native is proscribed in the liberal humanist tradition of modernity. Mavelimanrom on the other hand is marked by an attempt at understanding the 'native' before the process of his/her becoming a native is initiated by the colonizer. So it evinces a consciousness preceding colonization, which becomes the mark of the spatial identity of the 'manrom'.

The narration of the myth of the Manromis used to establish and consolidate the local identity of the subaltern. Mavelimanrom is the conceptual space created through the resistance propaganda of the myth of the 'manrom'. When the home of the Adiyors, the natural habitat is colonized, the myth of the Manrombecomes an attempt to resist looking at 'home' with the gaze of the colonizer. So remembering the original home, remembering and narrating the Manromin one's own language, in the oral traditions of tribe becomes a mode of resistance to the colonial epistemology. The myth of the 'manrom' thus gives a material and ideological identity to the 
subaltern, which transcends the boundaries of the nation state. So the 'manrom' becomes an epistemological, cultural and spatial symbol of the transformative resistance of the 'Adiyors'. Narrating the Manromthus amounts to narrating a cultural identity and thereby creating a spatial identity for the subaltern. The keeping alive of the memory, myth and songs ('thudippattu') even at the cost of risking lives becomes an act of revolutionary consciousness. In contrast, state hegemony, nationalist ideology, dominant language and cultural interpellation - all collude to construct the native of Kocharethi as a passive subject.

By producing an alternative discourse of gendered subalternity, mavelimanrom becomes the site of an ideological warfare. Veering away from the stereotypical portrayal of women in much of mainstream Malayalam writing, the women of the novel are portrayed as possessing a strong individual and sexual identity. Refusing to be confined to sexually defined roles, they write themselves into the text through their life and struggles. With a strong sense of their own history and collective identity, they evince knowledge of their role as important links in a secret tradition of solidarity and resistance. One comes across a vibrant woman's subculture, kept alive through mutual interactions and exchange of stories and songs. This is what prompts them to forge new bonds with their past, a bonding in sisterhood, which fires the memory of 'Keeyorathi', their great ancestor in the flight for freedom.

As the narrative unfolds, the reader is caught in the realization that the subaltern man's experience of oppression is different from the subaltern woman's experience and the focus 
shifts to the shaping of patriarchy by class, caste and colonialism.

The reconsolidation of native patriarchy by imperial power is countered in Mavelimanrom by recharging the old myths with new possibilities of meaning. In one of the most powerful feminist critiques ever attempted in Malayam literature Mavelimanrom offers a scathing attack of the hegemonic, nationalist, patriarchal code, completely subverting its discourses which represent the subaltern as the domesticated 'other'. The subaltern women of Mavelimanrom Chambi, Jevani and Ira - take a vow not to be impregnated by any man subscribing to this patriarchal code. The dominant tradition of imaging the land as women also glorifies woman's fertility and her capacity to nurture. Not giving birth by willful abortion becomes an act of defiant subversion. Refusing gender-specific roles, the women also refuse representation in the paradigms of the sexual/maternal body.

Rape as a prominent signifier in Mavelimanrom is used as an analogue for the violation of the land and other economic and political exploitations. Those blatant descriptions of rape are often used to reveal the rape mentality of the colonizer more than the experience of the oppressed women. Women's bodies thus become larger battlegrounds where greater territorial and cultural battles are waged; the gendered subalterns of Mavelimanrom are choked by the power of the colonial master, even over their reproductive capacities. Denied all sense of subjectivity, positioned as sexual merchandise and forced to breed a slave class to cater to the needs of colonialism's labour market, the subaltern women is forced to present her sexual, social and reproductive labours as 
offering before the Master. And yet the women of Mavelimanrom speak. Rejecting patriarchal, feudal or imperial norms of caste and class, they join together, refusing to break up under the phallic rule. They stand testimony to the subaltern's muted voice-consciousness. Thus, Mavelimanrom attempts an epistemic unsettling of both patriarchy and imperialism by turning to the archives of colonial dominance to unearth the ideology of patriarchal canons.

In contrast Kocharethi embraces and enhances the task of colonial modernity to instill middle class values and bourgeois virtues into the gendered 'national' subaltern subject. The new woman, conscious of her identity, is at the same time out of her roots. As Parvathy, the educated subaltern migrates to the city, the narrative, in an allegorical twist leaves Kochuraman and Kunjipennu stranded in a government hospital, at the mercy of state welfare aids. Thus one sees the articulation of gender being translated into a different idiom by the interventions of the modern state. Narayan assumes a nationalist identity by which he sees the education of subaltern women as necessary, but not at the cost of losing the essence of their 'femininity' and 'culture'. The ideological distance from Javani and Ira to Kunjipennu is a space articulated by a translated colonial discourse, which constructs the woman as the upholder of tradition, an embodiment of its representation. Kunjipennu sees Parvathy's education as encroaching upon her feminine essence. Kunjipennu is thus made to fit into the ideological framework of the nationalist narration of woman. Though the need for education of women is presented as imperative, the anxiety that it might devalue feminine virtues like chastity, modesty, patience and devotion persists. Here as before, one can see caste Hindu signs and symbols translated 
into the tribal discourse. Thus the process of subjection of the subaltern woman under new patriarchal codes of upper caste Hinduism is initiated. The uniqueness of Mavelimanrom as a subaltern text is that it creates a history for the subaltern, where the female subject has a speaking voice and participates in insurgency. Whereas in Mavelimanrom Kaippadan and Ira share the responsibility of sowing the seeds of the 'manrom'; the women of Kocharethi have no role in the struggle for independence. As Parvathy inhabits the secure space of her home, Madhavan and his comrades go out into the public domain to free the nation, thus lending their subaltern identities to structure the hegemony of a patriarchal nationalist culture.

A close reading of Kocharethi reveals the nuances through which gender and ethical relations become inextricably linked to the formation of the Indian state. Kocharethi is, in a sense, the tragic culmination of the heroic struggle waged by the women in Mavelimanrom over dominant, capitalist modes of production. The dream of the Manrom has transmogrified itself into the hard reality of the Indian nation state. Together, these novels provide a framework to picture the formation of India as a sovereign, socialist, democratic republic, where native and gender identities are subsumed and tokenized to strengthen the unifying logic of the nation.

Language is a fundamental site of struggle in subaltern discourses resisting translation, because colonization begins in language. The language of Mavelimanrom is an eclectic mixture of literary Malayalam, colloquial Malayalam, tribal Malayalam and the specific language of the Adiyors of 
Wayanad. The evident pull towards colonial modernity and nationalist themes in Kocharethi is found in its language too, which is very near standard Malayalam, the disjunctions being minimal. There is no attempt to capture the linguistic and cultural ethos of the language of the Malayaraya tribe. While in Mavelimanrom, language seeks to create a distance between the nation/empire and the subaltern space, in Kocharethi there is an attempted translation of this space. Mavelimanrom rejects the stylistic hierarchies of standard Malayalam and thus politically subverts its authorities. By introducing the music and method of tribal languages, their modes of expression and aspects of orality, Mavelimanrom underwrites the power invested in the print language. While destabilizing the standard language is a palpable project in Mavelimanrom, Kocharethi appropriates Malayalam and uses it to the contingencies of a different cultural context. Though the latter effect is in no way belittled, for it too produces a different culturally marked Malayalam - lexically, semantically and phonetically, the former offers a more radical approach to write the continually shifting subaltern subjectivities into a new indigenised language which does not conform to the paradigm of the formal Malayalam sociolect.

The received notion that the print language is the 'proper' language is done away with in the novel by endorsing the varied and various narratives are at endless play under the sign of a single language. The subaltern's simultaneous adoption of the roles of singer, story-teller, author and player, oppressed subject and resisting speaker creates the need for a language encapsulating such constantly shifting subjectivities. The inadequacy of the language of the centre to express the cognitive information of the peripheries and its inability to 
delineate subaltern group identity and culture crystallizes in Mavelimanrom's compulsion to stretch the norms of Malayalam language. New words are accommodated in the lexicon along with flagrant deviations in grammar, syntax, phonology, accent and structure, in the process toppling the authority of the colonial discourse. The songs or 'thudipattu', as an alternative discourse, becomes a powerful political and linguistic strategy of resistance. The songs and singing with all their associated cultural significations take on a disruptive function, carnivalising societal norms. In Kocharethi, one finds by contrast a silencing of the native tongue. That the arrival of nationalism and its accompanying cultural fictions proved effective in erasing those signs and symbols that problematize modernity and its project of homogenization is what a closer reading of Kocharethi reveals.

The subaltern community in Kocharethi, having lost its language, and having been translated and co-opted into the dominant discourse, has also lost the power to name. 'Parvathi', 'Madhavan', 'Narayanan' - all names of upper caste Hindu gods - speak of the silencing of a culture. A community devoid of its language is a community devoid of dignity. While Mavelimanrom emphasizes the linguistic and cultural validity of its language, Kocharethi is weighed down by the naming and interpolative functions of the dominant language in the process disempowering the subaltern's attempt to construct an identity.

For the subaltern interpolated in a dominant history, the very concept of history might bear the mark of an alien epistemology. But creating a narrative to historicize the tales of their ancestors 'Melorachan' and 'Keeyorathi' becomes a 
contingency for the subaltern, as it is only the tales of their travel that mark the site of the tribe's cultural and linguistic property. If Mavelimanrom is marked by a struggle to control, to write the history of one's tribe, for which is needed the power of language, Kocharethi is a giving-in, a passive surrender to the larger history of the nation state. In postcolonial parlance to have a history is to have a legitimate existence and what the latter text denies itself is this legitimacy of being. Thus while in Mavelimanrom the subaltern is seen to wrest agency, to wrest speech, in Kocharethi the subaltern is deftly muted by the dominant discourse. The discourse of the colonial modernity and the nation state that one finds in Kocharethi co-opts the native and re-fashions him/her according to the norms of the dominant culture. Whereas the space of colonial modernity is treated as inviolable in Kocharethi, it is critiqued and subverted by the resisting subaltern in Mavelimanrom. This is made possible by eschewing the ideologically contaminated language of the colonizer. The idiom and syntax of the native language are appropriated by the native subaltern for self-determination in the face of the exigencies of the colonial rule.

The interpolated language of Mavelimanrom is charged with the subaltern's sense of belonging to his/her place while the language of Kocharethi betrays the powerlessness of its non-belonging. Reviving the Manromin the language is a reappropriation of lost places, a refusal to be translated and transformed by colonial/national conception of space. If the conscious inscription of subaltern identity and place in language is what makes Mavelimanrom an interpolated historical narrative, it is the conceding of place, culture and language to the master narrative of the nation that makes 
Kocharethi an appropriated discourse of translated subaltern identity. Subaltern translations of the lingo of the nation and nationalism thus become acts of cultural displacement. Claiming the nation in the language also means being claimed by the nation.

\section{References}

Baby, K J. (1991). Mavelimanrom. Thrissur: Current Books.

Deleuze, Gilles and Guattari, Felix(1986). Kafka: Towards a Minor Literature. Trans. Dana Polan. Minneapolis: University of Minnesota.

Lyotard, Jean-Francois (1991). The Postmodern Explained to Children: Correspondence 1982-1985. Pefanis, Julian \& Thomas, Morgan (eds.) Sydney: Power Publications.

Menon, A Sreedhara (1991). A Survey of Kerala History. Madras: S Viswanathan.

Narayan, (1998). Kocharethi. Kottayam: DC Books.

Partha Chatterjee (1993). Nationalist Thought and the Colonial World: A Derivative Discourse. London: Zed Books. 
Spivak, Gayatri Chakravorty (1987). "A Literary Representation of the Sublatern: Mahasweta Devi's 'Stanadayini',' in Subaltern Studies V: Writings on South Asian History and Society. Guha, Ranaji. (ed.) Delhi: Oxford University Press.

Spivak, Gayatri Chakravorty (1988). "Can the Subaltern Speak?" in Nelson, Cary and Grossberg, Larry (eds.) Marxism and the Interpretation of Culture. Chicago: University of Illinois Press. 